\title{
RESEARCH BRIEF \\ Prevalence of Past-Year Dental Visit Among US Adults Aged 50 Years or Older, With Selected Chronic Diseases, 2018
}

\author{
Nita Patel, DrPH ${ }^{1}$; Rebecca Fils-Aime, $\mathrm{MPH}^{1,2}$; Chien-Hsun Li, MS ${ }^{3}$; Mei Lin, MD ${ }^{1}$; Valerie Robison, DDS ${ }^{1}$
}

\begin{abstract}
Accessible Version: www.cdc.gov/pcd/issues/2021/20_0576.htm
Suggested citation for this article: Patel N, Fils-Aime R, Li CH, Lin M, Robison V. Prevalence of Past-Year Dental Visit Among US Adults Aged 50 Years or Older, With Selected Chronic Diseases, 2018. Prev Chronic Dis 2021;18:200576. DOI: https:// doi.org/10.5888/pcd18.200576.
\end{abstract}

\section{PEER REVIEWED}

\section{Summary}

What is already known on this topic?

Although routine dental care is an important component of maintaining overall health, little is known about dental service utilization among adults with chronic conditions.

What is added by this report?

We found small but consistent lower dental service utilization among older adults with diabetes, heart disease or stroke, and chronic obstructive pulmonary disease compared with those without the disease after adjusting for sociodemographic characteristics. We also found lower dental service utilization among older adults who smoked and who had lower income, less education, and no health care coverage.

What are the implications for public health practice?

Our findings suggest the need to examine effective interventions to increase dental service utilization among at-risk and vulnerable populations.

\section{Abstract}

In this study, we used data from the Behavioral Risk Factor Surveillance System to conduct multivariable analyses to examine whether having selected chronic diseases was associated with lower past-year dental service utilization among US adults aged 50 years or older. We found consistent lower dental service utilization among older adults with diabetes, heart disease or stroke, and chronic obstructive pulmonary disease (COPD) compared with those without the disease after adjusting for sociodemographic characteristics. We also found lower dental service utilization among older adults with lower income, less education, and no health care coverage and among those who smoked. Effective interventions are needed to reduce disparities in access to dental care among at-risk and vulnerable populations.

\section{Objective}

Adults who report chronic conditions have a higher prevalence of unmet dental treatment needs (1) and resulting tooth loss (2) than their counterparts without chronic conditions; adults reporting diabetes, heart disease, or rheumatoid arthritis are at least $50 \%$ more likely to have severe tooth loss that results in difficulty eating healthy foods. Tentative evidence suggests that the level of the periodontal pathogens and inflammatory response from periodontal disease could increase the risk of systemic diseases such as cardiovascular disease (3). A Cochrane review (4) found evidence that treating periodontitis improved glycemic control among people with diabetes. Although routine dental care is an important component of maintaining overall health, little is known about dental service utilization among adults with chronic conditions.

\section{Methods}

We used data from the 2018 Behavioral Risk Factor Surveillance System (BRFSS), a cross-sectional, annual landline and cellular telephone survey of noninstitutionalized adults aged 18 years or older living in the 50 US states, the District of Columbia, and US territories on health-related risk behaviors, chronic health conditions, and use of preventive services (5). Individuals without teeth (ie, edentate) are less likely to see the dentist (6); we restricted our study population to respondents who had at least 1 permanent tooth and were aged 50 years or older $(\mathrm{N}=242,452)$.

The outcome variable, dental service utilization, was defined as visiting a dentist or dental clinic for any reason within the past year. We included chronic diseases associated with periodontal disease: arthritis, diabetes, heart diseases, and chronic obstructive pulmonary disease (COPD). We categorized heart attack, stroke, and coronary heart disease as heart disease. We assessed smoking 
status, a well-established risk factor for periodontal disease (7). Current cigarette smoking was defined as answering yes to the question, "Have you smoked at least 100 cigarettes in your entire life?" and answering "every day" or "some days" to the question, "Do you now smoke cigarettes every day, some days, or not at all?"

Analysis was conducted using SAS-Callable SUDAAN (SAS Institute, Inc) to account for the complex sampling design. For bivariate analyses, we used $\chi^{2}$ tests to calculate prevalence of pastyear dental visit by chronic conditions, regions, and selected sociodemographic characteristics. We used $t$ tests for the multivariable analysis to determine adjusted prevalence ratios (aPRs) and 95\% CIs for having a past-year dental visit by chronic conditions, adjusting for age, sex, race/ethnicity, annual household income, education, health care coverage, cigarette smoking status, and region. Significance was set at $P<.001$.

\section{Results}

Approximately 7 in 10 dentate adults aged 50 years or older reported having a dental visit in the past year (72.4\%) (Table 1). Crude prevalence of past-year dental visit was lower among adults who were male; were aged 50 to 64 years; were non-Hispanic black, Hispanic, or non-Hispanic other; had less than a college or technical school education; had an annual household income less than $\$ 75,000$; had no health care coverage; and resided in regions other than the Northeast (Table 2). Crude prevalence of having a pastyear dental visit was lower among older adults with arthritis; diabetes; heart attack, stroke, or coronary heart disease; and COPD. Current and former smokers were also less likely to have a past year dental visit than nonsmokers (Table 2).

In the adjusted model, older adults with diabetes; heart attack, stroke, or coronary heart disease; or COPD consistently had significantly lower dental service utilization compared with those without the disease, although the magnitude of the associations was small (Table 2). In addition, the associations between pastyear dental visit and education, income, health insurance coverage, and cigarette smoking status remained pronounced in the adjusted model. Having a past-year dental visit was lower among older adults who did not graduate from high school (aPR, 0.77; 95\% CI, 0.74-0.81), who had an annual household income $<\$ 24,999$ (aPR, $0.70 ; 95 \% \mathrm{CI}, 0.68-0.72)$, or were without health care coverage (aPR, 0.75; 95\% CI, 0.70-0.79) than older adults with a college degree or higher education, with an annual household income of $\$ 75,000$ or more, or with health care coverage. Current smokers had lower dental service utilization than never smokers (aPR, 0.82 ; 95\% CI, 0.79-0.85).

\section{Discussion}

To our knowledge, our study is the first to describe dental service utilization among older adults with selected chronic diseases. Although the magnitude of the association was small, we found consistently lower dental service utilization among older adults with diabetes, heart disease or stroke, and COPD, even after adjusting for sociodemographic characteristics. Similar to other studies $(8,9)$, we found that disparities in dental service utilization among older adults continue to persist by education, income, and health insurance status, as well as among cigarette smokers.

Lower dental service utilization among older adults could be, in part, due to loss of employer-based health insurance after retirement. Not all adults who have health insurance have dental insurance. Original Medicare does not provide routine dental services. Medicare Advantage Plans may cover dental services, but level of dental services and out-of-pocket costs vary by plan. We found that having chronic conditions was a barrier to dental service utilization. Individuals with systemic or chronic diseases are likely to prioritize their medical needs (9) over dental needs. Also, poor health associated with some chronic diseases could limit mobility among the elderly and subsequently affect access to dental services (9).

In 2011, the Institute of Medicine proposed integrating oral health with the medical health care system to promote better health and improve access to both dental and medical preventive services (10). Our findings suggest the need to have continued national dialogue to foster interprofessional and interprogram collaboration, examine how oral health care and medical care intersect, and identify opportunities where the 2 disparate health systems can potentially integrate to facilitate better care coordination for older adults with chronic diseases. Additional strategies may include systematically reviewing examples of successful models of medical-dental integration to identify best practices that increase dental service utilization among older adults with chronic diseases. Some short-term strategies may include educating health care providers about the higher need for routine dental care among older adults with chronic diseases.

Our study had several limitations. First, BRFSS data are selfreported and subject to both recall and social desirability bias. Second, BRFSS does not assess dental insurance coverage. Our use of health care coverage as a proxy indicator for dental insurance may have resulted in underestimation of dental service utilization.

In conclusion, effective interventions are needed to reduce disparities in access to dental care among at-risk and vulnerable populations.

\footnotetext{
The opinions expressed by authors contributing to this journal do not necessarily reflect the opinions of the U.S. Department of Health and Human Services, the Public Health Service, the Centers for Disease Control and Prevention, or the authors' affiliated institutions.
} 


\section{Acknowledgments}

The authors have no financial disclosures or conflicts of interest to report. The findings and conclusions in this report are those of the authors and do not necessarily represent the official position of the Centers for Disease Control and Prevention. No copyrighted materials were used in this research.

\section{Author Information}

Corresponding Author: Nita Patel, DrPH, Division of Oral Health, Centers for Disease Control and Prevention, 4770 Buford Highway, MS S107-8, Atlanta, GA 30341-3717. Telephone: 404639-8706. E-mail:nfp5@cdc.gov.

Author Affiliations: ${ }^{1}$ Centers for Disease Control and Prevention, Division of Oral Health, Atlanta, Georgia. ${ }^{2}$ Now with Emory University, Atlanta, Georgia. ${ }^{3}$ CyberData Technologies Inc, Herndon, Virginia.

\section{References}

1. Griffin SO, Barker LK, Griffin PM, Cleveland JL, Kohn W. Oral health needs among adults in the United States with chronic diseases. J Am Dent Assoc 2009;140(10):1266-74.

2. Parker ML, Thornton-Evans G, Wei L, Griffin SO. Prevalence of and changes in tooth loss among adults aged $\geq 50$ years with selected chronic conditions - United States, 1999-2004 and 2011-2016. MMWR Morb Mortal Wkly Rep 2020; 69(21):641-6.

3. Beck J, Offenbacher S. Systemic effects of periodontitis: epidemiology of periodontal disease and cardiovascular disease. J Periodontol 2005;76(11S):2089-100.

4. Simpson T, Weldon J, Worthington H, Needleman I, Wild S, Moles D, et al. Treatment of periodontal disease for glycaemic control in people with diabetes mellitus. Cochrane Database Syst Rev 2015;(11):CD004714.

5. Behavioral Risk Factor Surveillance System: overview: BRFSS 2016. Atlanta (GA): Centers for Disease Control and Prevention; 2016. https://www.cdc.gov/brfss/annual_data/ 2016/pdf/overview_2016.pdf. Accessed March 23, 2021.

6. Macek MD, Cohen LA, Reid BC, Manski RJ. Dental visits among older U.S. adults, 1999: the roles of dentition status and cost. J Am Dent Assoc 2004;135(8):1154-62, quiz 1165.

7. Kinane DF, Chestnutt IG. Smoking and periodontal disease. Crit Rev Oral Biol Med 2000;11(3):356-65.
8. Lutfiyya MN, Gross AJ, Soffe B, Lipsky MS. Dental care utilization: examining the associations between health services deficits and not having a dental visit in past 12 months. BMC Public Health 2019;19(1):265.

9. Kiyak HA, Reichmuth M. Barriers to and enablers of older adults' use of dental services. J Dent Educ 2005;69(9):975-86.

10. Advancing Oral Health in America. Washington (DC); Institute of Medicine of the National Academies; 2011.

The opinions expressed by authors contributing to this journal do not necessarily reflect the opinions of the U.S. Department of Health and Human Services, the Public Health Service, the Centers for Disease Control and Prevention, or the authors' affiliated institutions. 


\section{Tables}

Table 1. Percentage of Dentate ${ }^{a}$ Adults Aged $\geq 50$ Years, by Selected Characteristics, Behavioral Risk Factor Surveillance System, United States, 2018

\begin{tabular}{|c|c|c|}
\hline Characteristic & No. of Respondents $(\mathrm{N}=\mathbf{2 4 2 , 4 5 2 )}$ & Weighted Percentage (SE) \\
\hline \multicolumn{3}{|c|}{ Demographic Characteristics } \\
\hline \multicolumn{3}{|l|}{ Age, $y$} \\
\hline $50-64$ & 115,367 & $57.6(0.2)$ \\
\hline$\geq 65$ & 127,085 & $42.4(0.2)$ \\
\hline \multicolumn{3}{|l|}{ Sex } \\
\hline Male & 105,672 & $46.9(0.2)$ \\
\hline Female & 136,239 & $53.1(0.2)$ \\
\hline \multicolumn{3}{|l|}{ Race/ethnicity } \\
\hline Non-Hispanic White & 197,581 & $73.4(0.3)$ \\
\hline Non-Hispanic Black & 17,628 & $9.9(0.1)$ \\
\hline Hispanic & 10,229 & $10.6(0.2)$ \\
\hline Non-Hispanic other & 12,305 & $6.1(0.2)$ \\
\hline \multicolumn{3}{|l|}{ Education } \\
\hline Did not graduate from high school & 13,679 & $11.8(0.2)$ \\
\hline High school graduate & 63,005 & $26.7(0.2)$ \\
\hline Attended college or technical school & 66,414 & $31.4(0.2)$ \\
\hline College or technical school graduate & 98,577 & $30.2(0.2)$ \\
\hline \multicolumn{3}{|l|}{ Annual household income, $\$$} \\
\hline$\leq 24,999$ & 44,697 & $23.2(0.2)$ \\
\hline $25,000-49,999$ & 49,689 & $23.2(0.2)$ \\
\hline $50,000-74,999$ & 34,540 & $16.1(0.2)$ \\
\hline$\geq 75,000$ & 70,203 & $37.4(0.2)$ \\
\hline \multicolumn{3}{|l|}{ Health care coverage } \\
\hline Yes & 230,679 & $93.6(0.1)$ \\
\hline No & 11,129 & $6.4(0.1)$ \\
\hline \multicolumn{3}{|l|}{ US region $^{\mathrm{b}}$} \\
\hline Northeast & 78,648 & $24.1(0.2)$ \\
\hline Southeast & 35,943 & $20.3(0.1)$ \\
\hline Southwest & 18,490 & $11.3(0.2)$ \\
\hline Midwest & 55,579 & $20.8(0.1)$ \\
\hline
\end{tabular}

${ }^{\text {a }}$ Dentate is defined as individuals with at least 1 permanent tooth.

${ }^{b}$ For our analysis, the Northeast region includes HHS Regions 1 (Maine, Massachusetts, New Hampshire, Rhode Island, and Vermont), 2 (New Jersey, New York), and 3 (District of Columbia, Maryland, Pennsylvania, Virginia, and West Virginia); the Southeast region includes HHS Region 4 (Alabama, Florida, Georgia, Kentucky, Mississippi, North Carolina, South Carolina, and Tennessee); the Southwest region includes HHS Region 6 (Arkansas, Louisiana, New Mexico, Oklahoma and Texas); the Midwest region includes HHS Regions 5 (Indiana, Illinois, Michigan, Minnesota, Ohio, and Wisconsin) and 7 (lowa, Kansas, Missouri, and Nebraska); and the West region includes HHS Regions 8 (Colorado, Montana, North Dakota, South Dakota, Utah and Wyoming), 9 (Arizona, California, Hawaii, Nevada), and 10 (Alaska, Idaho, Oregon, and Washington). 
(continued)

Table 1. Percentage of Dentate ${ }^{a}$ Adults Aged $\geq 50$ Years, by Selected Characteristics, Behavioral Risk Factor Surveillance System, United States, 2018

\begin{tabular}{|c|c|c|}
\hline Characteristic & No. of Respondents $(\mathrm{N}=\mathbf{2 4 2 , 4 5 2 )}$ & Weighted Percentage (SE) \\
\hline West & 53,792 & $23.4(0.2)$ \\
\hline \multicolumn{3}{|c|}{ Health Status and Chronic Diseases } \\
\hline \multicolumn{3}{|l|}{ Arthritis } \\
\hline Yes & 107,730 & $41.6(0.2)$ \\
\hline No & 133,430 & $58.4(0.2)$ \\
\hline \multicolumn{3}{|l|}{ Diabetes } \\
\hline Yes & 42,415 & $18.3(0.2)$ \\
\hline No & 199,705 & $81.7(0.2)$ \\
\hline \multicolumn{3}{|c|}{ Heart attack, stroke, or coronary heart disease } \\
\hline Yes & 36,703 & $14.3(0.2)$ \\
\hline No & 205,653 & $85.7(0.2)$ \\
\hline \multicolumn{3}{|c|}{ Chronic obstructive pulmonary disease } \\
\hline Yes & 22,762 & $9.3(0.1)$ \\
\hline No & 218,478 & $90.7(0.1)$ \\
\hline \multicolumn{3}{|c|}{ History of cigarette smoking } \\
\hline Current smoker & 25,509 & $12.0(0.2)$ \\
\hline Former smoker & 77,314 & $32.1(0.2)$ \\
\hline Never smoked & 131,447 & $55.9(0.2)$ \\
\hline \multicolumn{3}{|c|}{ Past-year dental visit } \\
\hline Yes & 180,015 & $72.4(0.2)$ \\
\hline No & 60,612 & $27.6(0.2)$ \\
\hline
\end{tabular}

${ }^{\text {a }}$ Dentate is defined as individuals with at least 1 permanent tooth.

${ }^{b}$ For our analysis, the Northeast region includes HHS Regions 1 (Maine, Massachusetts, New Hampshire, Rhode Island, and Vermont), 2 (New Jersey, New York), and 3 (District of Columbia, Maryland, Pennsylvania, Virginia, and West Virginia); the Southeast region includes HHS Region 4 (Alabama, Florida, Georgia, Kentucky, Mississippi, North Carolina, South Carolina, and Tennessee); the Southwest region includes HHS Region 6 (Arkansas, Louisiana, New Mexico, Oklahoma and Texas); the Midwest region includes HHS Regions 5 (Indiana, Illinois, Michigan, Minnesota, Ohio, and Wisconsin) and 7 (lowa, Kansas, Missouri, and Nebraska); and the West region includes HHS Regions 8 (Colorado, Montana, North Dakota, South Dakota, Utah and Wyoming), 9 (Arizona, California, Hawaii, Nevada), and 10 (Alaska, Idaho, Oregon, and Washington). 
Table 2. Crude Prevalence and Adjusted Prevalence Ratio of Past-Year Dental Visit Among Dentate ${ }^{a}$ Adults Aged $\geq 50$ Years, Behavioral Risk Factor Surveillance System, United States, 2018

\begin{tabular}{|c|c|c|c|c|}
\hline Characteristic & Crude Prevalence of Past-Year Dental Visit (95\% Cl) & $P$ Value $^{\mathrm{b}}$ & aPR $(95 \% \mathrm{Cl})$ & $P$ Value $^{\mathrm{c}}$ \\
\hline Overall & $72.4(72.0-72.8)$ & NA & NA & NA \\
\hline \multicolumn{5}{|l|}{ Sex } \\
\hline Male & $69.9(69.2-70.5)$ & \multirow[t]{2}{*}{$<.001$} & \multicolumn{2}{|r|}{1 [Reference] } \\
\hline Female & $74.7(74.1-75.2)$ & & $1.08(1.07-1.10)$ & $<.001$ \\
\hline \multicolumn{5}{|l|}{ Age, y } \\
\hline $50-64$ & $70.8(70.2-71.3)$ & \multirow[t]{2}{*}{$<.001$} & \multicolumn{2}{|r|}{$1[$ Reference $]$} \\
\hline$\geq 65$ & $74.6(74.0-75.3)$ & & $1.06(1.05-1.08)$ & $<.001$ \\
\hline \multicolumn{5}{|l|}{ Race/ethnicity } \\
\hline Non-Hispanic White & $76.0(75.6-76.4)$ & \multirow[t]{4}{*}{$<.001$} & \multicolumn{2}{|r|}{1 [Reference] } \\
\hline Non-Hispanic Black & $60.3(58.7-61.8)$ & & $0.92(0.89-0.94)$ & $<.001$ \\
\hline Hispanic & $60.3(58.2-62.4)$ & & $1.00(0.97-1.04)$ & 0.82 \\
\hline Non-Hispanic other & $70.1(67.4-72.7)$ & & $0.97(0.93-1.01)$ & 0.09 \\
\hline \multicolumn{5}{|l|}{ Education } \\
\hline Did not graduate from high school & $48.7(46.8-50.7)$ & \multirow[t]{4}{*}{$<.001$} & $0.77(0.74-0.81)$ & $<.001$ \\
\hline High school graduate & $66.7(65.9-67.5)$ & & $0.91(0.89-0.92)$ & $<.001$ \\
\hline Attended some college or technical school & $73.9(73.1-74.6)$ & & $0.95(0.94-0.97)$ & $<.001$ \\
\hline College or technical school graduate & $85.1(84.6-85.6)$ & & \multicolumn{2}{|r|}{1 [Reference] } \\
\hline \multicolumn{5}{|l|}{ Annual household income, $\$$} \\
\hline$\leq 24,999$ & $51.6(50.5-52.7)$ & \multirow[t]{4}{*}{$<.001$} & $0.70(0.68-0.72)$ & $<.001$ \\
\hline $25,000-49,999$ & $67.0(66.0-68.1)$ & & $0.83(0.82-0.85)$ & $<.001$ \\
\hline $50,000-74,999$ & $77.8(76.7-78.8)$ & & $0.93(0.92-0.95)$ & $<.001$ \\
\hline$\geq 75,000$ & $86.2(85.6-86.7)$ & & \multicolumn{2}{|r|}{1 [Reference] } \\
\hline \multicolumn{5}{|l|}{ Health care coverage } \\
\hline Yes & $74.3(73.9-74.7)$ & \multirow[t]{2}{*}{$<.001$} & \multicolumn{2}{|r|}{1 [Reference] } \\
\hline No & $44.9(42.7-47.2)$ & & $0.75(0.70-0.79)$ & $<.001$ \\
\hline \multicolumn{5}{|l|}{ Arthritis } \\
\hline Yes & $71.4(70.7-72.0)$ & \multirow[t]{2}{*}{$<.001$} & $1.01(1.00-1.02)$ & .16 \\
\hline No & $73.2(72.6-73.8)$ & & \multicolumn{2}{|r|}{1 [Reference] } \\
\hline Diabetes & & & & \\
\hline
\end{tabular}

Abbreviations: aPR, adjusted prevalence ratio; COPD, chronic obstructive pulmonary disease; NA, not applicable.

${ }^{a}$ Dentate is defined as individuals with at least 1 permanent tooth.

${ }^{\mathrm{b}}$ Chi-square test was used for the bivariate analysis.

${ }^{\mathrm{c}} t$ test was used for the adjusted prevalence ratio analysis.

${ }^{d}$ For our analysis, the Northeast region includes HHS Regions 1 (Maine, Massachusetts, New Hampshire, Rhode Island, and Vermont), 2 (New Jersey, New York), and 3 (District of Columbia, Maryland, Pennsylvania, Virginia, and West Virginia); the Southeast region includes HHS Region 4 (Alabama, Florida, Georgia, Kentucky, Mississippi, North Carolina, South Carolina, and Tennessee); the Southwest region includes HHS Region 6 (Arkansas, Louisiana, New Mexico, Oklahoma and Texas); the Midwest region includes HHS Regions 5 (Indiana, Illinois, Michigan, Minnesota, Ohio, and Wisconsin) and 7 (lowa, Kansas, Missouri, and Nebraska); and the West region includes HHS Regions 8 (Colorado, Montana, North Dakota, South Dakota, Utah and Wyoming), 9 (Arizona, California, Hawaii, Nevada), and 10 (Alaska, Idaho, Oregon, and Washington). 
(continued)

Table 2. Crude Prevalence and Adjusted Prevalence Ratio of Past-Year Dental Visit Among Dentate ${ }^{a}$ Adults Aged $\geq 50$ Years, Behavioral Risk Factor Surveillance System, United States, 2018

\begin{tabular}{|c|c|c|c|c|}
\hline Characteristic & Crude Prevalence of Past-Year Dental Visit (95\% Cl) & $P$ Value $^{\mathrm{b}}$ & aPR $(95 \% \mathrm{Cl})$ & $P$ Value $^{\mathrm{c}}$ \\
\hline Yes & $64.7(63.6-65.9)$ & \multirow[t]{2}{*}{$<.001$} & $0.95(0.93-0.97)$ & $<.001$ \\
\hline No & $74.1(73.7-74.6)$ & & \multicolumn{2}{|r|}{1 [Reference } \\
\hline \multicolumn{5}{|c|}{ Heart attack, stroke, or coronary heart disease } \\
\hline Yes & $63.9(62.7-65.0)$ & \multirow[t]{2}{*}{$<.001$} & $0.95(0.92-0.97)$ & $<.001$ \\
\hline No & $73.8(73.4-74.3)$ & & \multicolumn{2}{|r|}{1 [Reference } \\
\hline \multicolumn{5}{|l|}{ COPD } \\
\hline Yes & $59.3(57.7-60.8)$ & \multirow[t]{2}{*}{$<.001$} & $0.93(0.91-0.96)$ & $<.001$ \\
\hline No & $73.8(73.4-74.3)$ & & \multicolumn{2}{|r|}{1 [Reference] } \\
\hline \multicolumn{5}{|c|}{ History of cigarette smoking } \\
\hline Current smoker & $53.3(51.9-54.8)$ & \multirow[t]{3}{*}{$<.001$} & $0.82(0.79-0.85)$ & $<.001$ \\
\hline Former smoker & $73.0(72.3-73.7)$ & & $0.98(0.97-0.99)$ & 0.001 \\
\hline Never smoked & $76.3(75.7-76.8)$ & & \multicolumn{2}{|r|}{1 [Reference] } \\
\hline \multicolumn{5}{|l|}{ US region $^{\mathrm{d}}$} \\
\hline Northeast & $76.2(75.4-76.8)$ & \multirow[t]{5}{*}{$<.001$} & \multicolumn{2}{|r|}{1 [Reference] } \\
\hline Southeast & $69.4(68.5-70.3)$ & & $0.97(0.95-0.98)$ & $<.001$ \\
\hline Southwest & $64.7(62.7-66.7)$ & & $0.91(0.88-0.94)$ & $<.001$ \\
\hline Midwest & $74.3(73.6-74.9)$ & & $0.99(0.98-1.01)$ & .33 \\
\hline West & $73.2(72.2-74.1)$ & & $0.97(0.96-0.99)$ & .001 \\
\hline
\end{tabular}

Abbreviations: aPR, adjusted prevalence ratio; COPD, chronic obstructive pulmonary disease; NA, not applicable.

${ }^{a}$ Dentate is defined as individuals with at least 1 permanent tooth.

${ }^{\mathrm{b}}$ Chi-square test was used for the bivariate analysis.

${ }^{c} t$ test was used for the adjusted prevalence ratio analysis.

${ }^{d}$ For our analysis, the Northeast region includes HHS Regions 1 (Maine, Massachusetts, New Hampshire, Rhode Island, and Vermont), 2 (New Jersey, New York), and 3 (District of Columbia, Maryland, Pennsylvania, Virginia, and West Virginia); the Southeast region includes HHS Region 4 (Alabama, Florida, Georgia, Kentucky, Mississippi, North Carolina, South Carolina, and Tennessee); the Southwest region includes HHS Region 6 (Arkansas, Louisiana, New Mexico, Oklahoma and Texas); the Midwest region includes HHS Regions 5 (Indiana, Illinois, Michigan, Minnesota, Ohio, and Wisconsin) and 7 (lowa, Kansas, Missouri, and Nebraska); and the West region includes HHS Regions 8 (Colorado, Montana, North Dakota, South Dakota, Utah and Wyoming), 9 (Arizona, California, Hawaii, Nevada), and 10 (Alaska, Idaho, Oregon, and Washington).

The opinions expressed by authors contributing to this journal do not necessarily reflect the opinions of the U.S. Department of Health and Human Services, the Public Health Service, the Centers for Disease Control and Prevention, or the authors' affiliated institutions. 